\title{
Ten papers for teachers of evidence-based medicine and health care: Sicily workshop 2019
}

\author{
David Nunan $\mathbb{C}^{1,, 2}$ Adrienne Lindblad, ${ }^{3}$ \\ Indah S Widyahening, ${ }^{4}$ Wanderley M Bernardo, ${ }^{5}$ \\ Ching-Chi Chi 이 , ${ }^{6,7}$ Fiona Cowdell, ${ }^{8}$ Karen Becker, ${ }^{9}$ \\ Shadia Constantine,${ }^{10}$ Christine East, ${ }^{11}$ Hilde T Myrhaug, ${ }^{12,13}$ \\ Susanne Grødem Johnson 지 , ${ }^{14}$ Edmund Jack, ${ }^{15,16}$ \\ Rachel Thompson ${ }^{0},{ }^{17}$ Haris Achilleos, ${ }^{18}$ Rigmor C Berg, ${ }^{19}$ \\ Anne Kristin Snibsøer, ${ }^{20}$ Lucian Puscasiu, ${ }^{21}$ \\ Marie-Louise EL Bartelink (1), ${ }^{22}$ Petra G van Peet, ${ }^{23}$ \\ Franco Berti, ${ }^{24}$ Julie Tilson, ${ }^{25}$ Kari AO Tikkinen (1) , ${ }^{26,27}$ \\ Loai Albarqouni, ${ }^{28}$ Peter Hoegen (1) ${ }^{29}$
}

For numbered affiliations see end of article.

Correspondence to: Dr David Nunan, Primary Care Health Sciences, University of Oxford, Oxford OX1 2JD, UK; david.nunan@phc.ox.ac.uk

Check for updates

( $)$ Author(s) (or their employer(s)) 2020. No commercial re-use. See rights and permissions. Published by BMJ.

To cite: Nunan D, Lindblad A, Widyahening IS, et al. BMJ Evidence-Based Medicine Epub ahead of print: [please include Day Month Year]. doi:10.1136/ bmjebm-2020-111479

\section{Introduction}

A previous article sought to signpost papers that were considered helpful when starting on the journey of practicing evidence-based medicine (EBM). ${ }^{1}$ The lead author was invited to run a workshop at the Eighth Conference of the International Society for Evidence-Based Health Care run in collaboration with the Gruppo Italiano per la Medicina Basata sulle Evidenze from 6 November to 9 November 2019. The aim of the workshop was to challenge a group of teachers and educators to consider useful papers for the teaching of EBM/evidence-based healthcare (EBHC). The second aim was to start a database of such studies. The third aim was to share learning and foster discussion from the workshop through journal publication. EBM and EBHC are used interchangeable throughout this article.

\section{Article selection process}

Working in eight small groups (three to five people), teachers and researchers of EBM/EBHC $(n=29)$ first listed any articles that they considered useful for new teachers starting out their teaching journey. So that the challenge also acted as learning for the participants, they were deliberately not briefed on the full nature of the workshop (eg, the consideration and selection of specific articles). After $15 \mathrm{~min}$, each group spent another $10 \mathrm{~min}$ selecting their top three articles from their original list (if this list had more than three papers). This was followed by another $5 \mathrm{~min}$ selecting their final article to put forward for this paper consensus and any disagreements resolved via discussion. Groups had to provide the following information for each paper: authors; year of publication; title; reason(s) for inclusion; link to paper/reference. Learning from previous experiences, the workshop lead (DN) instructed that a group could not select an article for which a group member was an author thus avoiding one possible source of conflict. As a group we felt that this specific rule of the article selection process was fair, and while acknowledging the potential for exclusion of relevant articles, the consensus was that if, out of a group of 30 or so teachers of EBM, a specific paper from one of the author's in the room was not mentioned then it was a sign that it had at least not reached a level of importance/dissemination to a group of teachers attending one of the leading conferences for EBM/EBHC educators.

That said there was more than one article authored by a workshop participant selected by other group participants at the various stages, including one that made the final manuscript.

The groups worked in real time on a Google spreadsheet (database) which simultaneously acted to populate a database of articles. Following the workshop, the lead author attempted to contact all workshop participants via email to ascertain if they wanted to be authors on this publication. Four participants (three from the same group) declined authorship and acknowledgement and one participant declined authorship but accepted acknowledgement. One participant was non-responsive to emails and was excluded from authorship. The majority of groups were unable to provide a detailed synopsis of their chosen article and they therefore performed this task after the workshop as part of drafting this manuscript. Here we present the final set of papers from seven groups, presented in group order. To arrive at 'Ten' papers, the lead author (DN) added their selected articles to the same database as other participants in the workshop. From this, he selected his top three $(8,9,10)$. Coauthors of the paper were emailed and offered the opportunity to agree or disagree with these three suggested articles. All of the coauthors agreed with all three selected articles. 


\section{Selected articles}

Below are the selected articles. Numbering is based on group order and has no bearing in relation to importance.

\section{Sicily statement on evidence-based practice (EBP)}

The statement was developed as a result of an international meeting of EBHC teachers and developers representing various professions within the health sector in $2003 .^{2}$ The minimum standard educational requirement of evidence-based practitioners were compiled along with a summary of evidence-based teaching strategies to effectively deliver and evaluate the steps of EBP. The article emphasises the role of EBM/EBHC in the clinical decisionmaking process and summarises the evolution of EBM/EBHC to EBP in order to incorporate the diverse range of healthcare professions. The statement compiled five key steps in EBP that can be applied in both clinical practice and teaching, thus integrating medical education with clinical practice.

\section{Evidence-based guidelines or collectively constructed 'mindlines'? Ethnographic study of knowledge management in primary care}

The concept of 'mindlines' (collectively reinforced, internalised guidelines) challenges traditional thinking into how we teach EBP. They comprise an amalgamation and internalisation of experiences and interactions with colleagues and patients, opinion leaders and other sources of knowledge. ${ }^{3}$ Practitioners report their knowledge and practice is continually produced and transformed as they meld different types and sources of evidence and interact with colleagues and others. Current EBP teaching is underpinned by the five steps of EBP. While this model has merit, used alone it does not fully recognise the 'messiness' of knowledge acquisition and use in everyday practice. Using mindlines in teaching can bridge the gap between the steps of EBP and the reality of the clinical environment and raise the learners' awareness of the need to develop their 'contextual adroitness' as well as skills to make rapid, complex decisions. The inclusion and importance of this paper is reflected in the fact it was also selected by others as one of 10 papers for practicing EBM. ${ }^{1}$

\section{Core competencies in EBP for health professionals: consensus statement based on a systematic review and Delphi survey}

This paper reports a consensus on the core competencies of EBP that would ideally be achieved by a student of EBHC, from undergraduate to practising clinician, in any healthcare discipline. ${ }^{4}$ In providing direction on what 'should' be taught, it offers the opportunity to standardise learning across disciplines and countries. This can be augmented to help the teacher learn how to teach EBM/EBHC principles by referring to interventions identified by Young and colleagues. ${ }^{5}$

\section{Tips for teachers of EBM: relative risk reduction, absolute risk reduction and number needed to treat}

People find numbers hard to understand and apply in practice, but this is a crucial skill. Finding a simple way and useful examples to explain treatment effects is even harder. This paper demonstrates how to teach this directly, clearly and visually. ${ }^{6}$ The steps shown here can change the way the learner thinks by assisting the crossing of a troublesome learning threshold regarding the interpretation and application of effect sizes that is likely to be transformative for many learners. The learner can then interpret the results of treatment papers and apply them in their practice. This paper is one from a useful series 'Tips for learning and teaching evidence-based medicine.'

\section{Why most published research findings are false?}

The call this paper makes for well performed and relevant research is as important today as when it was published 15 years ago. ${ }^{8}$ Trial registration, publication bias, the dangers of multiple testing and a focus on finding significant $p$ values instead of clinically important effects are identified as key issues underpinning the astonishing fact that, in the authors view, 95\% of all published research is likely to be false. Errors due to overly specific questions and small sample sizes are addressed and it calls for studies with higher pre-study odds in order to improve the likelihood of real and true findings from research. Though some of the solutions put forward have been incorporated into research practice, this paper acts as a constant reminder in EBM teaching to always be critical about research findings and to be aware of the possible impact on clinical practice.

\section{EBM: a movement in crisis}

Teaching and learning in EBM/EBHC should not only consist of its merits in theory and in practice but also of its problems. In the previous ' 10 papers' article, ${ }^{1}$ awareness of common criticisms of EBM was acknowledged with reference to the systematic assessment by Straus and McAlister. ${ }^{9}$ Fourteen years on, Greenhalgh and colleagues ${ }^{10}$ focus on more contemporary issues, adopting a collaborative approach to not only identify the unintended consequences of EBM but to also offer some solutions. Issues of importance raised include the hijacking of the evidence-based 'quality mark' by vested interests, too much clinically irrelevant evidence, management-driven over patient-centred care and under-represented populations within the evidence base. Solutions to these problems are offered-including changes to current EBM training that goes beyond the first three steps and consider honing expert judgement and skills in shared decision making. Teachers and educators are thus provided with a useful and accessible synopsis to aid learners in grasping the nuances of EBP and reminding them of the need to refocus on its founding principles-'providing useful evidence that can be combined with context and professional expertise so that individual patients get optimal treatment'.

\section{The connection between shared decision making and EBP}

EBHC should always start and end with patients. This article highlights the connections between EBHC and shared decision making-both needed for optimal healthcare. ${ }^{11}$ With the increased availability of pre-appraised evidence, clinicians need skills to critically interpret and implement research evidence using shared decision making, often facilitated with tools to improve communication. Shared decision-making skills are crucial for inclusion of patients' values and preferences and for the practice of EBHC. This article points out that EBHC and shared decision making together reinforce the development of healthcare guidelines and not only the interaction between one patient and their clinicians. It ends unambiguously: 'Evidence-based medicine needs SDM (shared decision making), and SDM needs EBM. Patients need both. Teaching EBHC should, therefore, include teaching shared decision making-an area historically overlooked compared with the other EBHC steps. ${ }^{12}$

\section{What are the effects of teaching EBHC? Overview of systematic reviews}

In 2004, Coomarasamy and Khan published a systematic review examining postgraduate education and later proposed a hierarchy of teaching and learning in EBHC. ${ }^{13}{ }^{14}$ This important work sparked a growth in research assessing the effects of teaching EBHC 
using different approaches and target populations. Young and colleagues summarised this research in an overview of systematic reviews, including 16 reviews with 81 separate studies of teaching EBHC at undergraduate or postgraduate level. ${ }^{5}$ Findings resonated with Khan's hierarchy, noting EBHC teaching and learning strategies were most successful when implementing multifaceted, clinically integrated approaches with assessment. The authors also highlighted the need for rigorous research to identify minimum components for multifaceted interventions, assessment of medium to long-term outcomes and implementation of these interventions.

\section{Applying evidence to the individual patient}

A focus on the first three steps of EBHC (ask, acquire and appraise) has led to a relative dearth of information to support teaching of step four (apply). Using a clinical scenario, Straus and Sackett describe application of step four in practice. ${ }^{15}$ They describe how they apply evidence to the individual patient by first asking us to consider 'if our patient is so different from those included in the study that its results cannot be applied to him?' The concept of the ' $\mathrm{f}$ ' factor-their version of personalised medicine-is also introduced. Calling for more research on decision-support methods, they conclude 'Ultimately, the patient must be our guide-he is the one with the disease, the one that may undergo therapy (and experience the adverse events) and we must find ways of enhancing our communication of evidence to the patient and of improving the shared decision-making process'.

\section{David L Sackett: interview in 2014 and 2015}

Shortly after Dave was diagnosed with terminal cancer in 2014, two of his mentees, Iain Chalmers and Steve Goodman, urged a third, Haynes, to 'do something' to record Dave's thoughts on his remarkable life and career. The result was this interview. ${ }^{16}$ Indicating the importance Dave placed on educating the next generation, the words 'teach', 'teaching', 'teacher', 'teaches', 'education' and 'educator' appear a total of 146 times. 'Practice' appears 45 times. On page 41, Dave provides two key lessons for any teacherinspiring change in your learners and practicing what you preach: 'The residents not only showed up and learnt, but became threatening to some of the faculty, and we eagerly responded to the latters' requests for their own (separate) sessions [...]. Along the way, it was bolstered by a non-randomised trial conducted by the [...] graduate student Kathryn Bennett that demonstrated considerable improvements in critical appraisal skills among experimental, but not control, medical students'. This paper offers great insight into Dave's philosophy and practice of teaching EBM throughout his career.

\section{Summary}

The articles selected overlap on three broad themes useful for teachers of EBM/EBHC to consider: (1) 'back to basics'-a reminder of the EBHC journey and why teaching it matters (articles 1, 9 and 10); (2) practical resources-for specific elements and methods of teaching EBHC (articles 1, 3, 4, 7 and 8); and (3) challenges we face in teaching EBHC and that EBHC faces as a movement and practice (articles 2, 5 and 6)

The articles presented here reflect the preferences of teachers and educators from a diverse set of backgrounds under resource and time-restricted conditions. The final selected list is not designed to be exhaustive, nor comprehensive, nor the 'top' or 'best' articles on the topic of teaching EBHC. Indeed, some participants voiced this concern during the workshop, stressing their choices would likely have been different under different circumstances. One of the objectives of the workshop was the intentional act of putting teachers of EBHC 'on the spot'; to get them thinking about their own knowledge base and the resources they can signpost peers and colleagues to without much thought. Participants may have found this challenging. The hope is that participants walked away with having learnt something about themselves they may wish to improve on, while at the same time having a tangible output in the form of this paper. You may disagree with the final selections. We, however, found benefit discussing some of the articles that we consider useful in informing our own teaching and practice. We hope that this list will evolve and encourage fellow teachers and educators to suggest relevant articles to add to a database that we will look the share via the EBHC teachers website (www.teachingebhc.org). This can be done by contacting the lead author David Nunan via email (david.nunan@phc.ox.ac.uk).

The full slide set from the workshop is available here: www. EBHCconference.org

\section{Author affiliations}

${ }^{1}$ Primary Care Health Sciences, University of Oxford, Oxford, UK

${ }^{2}$ Centre for Evidence-Based Medicine, University of Oxford, Oxford, UK

${ }^{3}$ Alberta College of Family Physicians (PEER) and the Department of Family Medicine, University of Alberta, Edmonton, Alberta, Canada

${ }^{4}$ Department of Community Medicine, Faculty of Medicine, Universitas Indonesia, Depok, Indonesia

${ }^{5}$ Faculty of Medicine, University of Sao Paulo, Sao Paulo, Brazil ${ }^{6}$ Department of Dermatology, Chang Gung Memorial Hospital, Taoyuan, Taiwan

${ }^{7}$ College of Medicine, Chang Gung University, Taoyuan, Taiwan

${ }^{8}$ School of Nursing and Midwifery, Faculty of Health, Education and Life Sciences, Birmingham City University, Birmingham, United Kingdom ${ }^{9}$ Family and Social Medicine, Montefiore Medical Center, Albert Einstein College of Medicine, Bronx, New York, USA

${ }^{10}$ Internal Medicine, Sapporo Tokushukai Hospital, Sapporo, Japan

${ }^{11}$ School of Nursing and Midwifery \& Mercy Health, La Trobe University College of Science Health and Engineering, Bundoora, Victoria, Australia

${ }^{12}$ Division For Health Sciences, Norwegian Institute of Public Health, Oslo, Norway

${ }^{13}$ Faculty of Health Sciences, Oslo Metropolitan University, Oslo, Norway

${ }^{14}$ Department of Health and Functioning, Faculty of Health and Social

Sciences, Western Norway University of Applied Sciences, Bergen, Norway

${ }^{15}$ Yealm Medical Centre, Yealmton, UK

${ }^{16}$ PenARC (NIHR) Applied Research Collaboration (ARC) South West Peninsula, Exeter, United Kingdom

${ }^{17}$ Office of Medical Education, University of New South Wales, Sydney, New South Wales, Australia

${ }^{18}$ Paediatrics, Royal London Hospital Barts Health NHS Trust, London, UK

${ }^{19}$ Reviews and Health Technology Assessments, Norwegian Institute of

Public Health, Oslo, Norway

${ }^{20}$ Health and Caring Sciences, Faculty of Health and Social Sciences, Western Norway University of Applied Sciences, Bergen, Norway

${ }^{21}$ University of Medicine Pharmacy Science and Technology of Targu

Mures, Targu Mures, Romania

${ }^{22}$ General Practice, Julius Centre, UMC Utrecht, Utrecht, The Netherlands

${ }^{23}$ Public Health and Primary Care, Leiden University Medical Center,

Leiden, The Netherlands

${ }^{24}$ Gruppo Italiano per la Medicina Basata sulle Evidenze (GIMBE),

Bologna, Italy

${ }^{25}$ Division of Biokinesiology and Physical Therapy, University of Southern California, Los Angeles, California, USA

${ }^{26}$ Departments of Urology and Public Health, University of Helsinki and Helsinki University Hospital, Helsinki, Finland

${ }^{27}$ Department of Surgery, South Karelia Central Hospital, Lappeenranta, Finland

${ }^{28}$ Institute for Evidence-Based Healthcare, Faculty of Health Sciences and Medicine, Bond University, Gold Coast, Queensland, Australia

${ }^{29}$ School of Health and Social Care, Avans University of Applied Science, Breda, The Netherlands 
Twitter David Nunan @dnunan79, Loai Albarqouni @ loaialbarqouni and Peter Hoegen @alsook

Acknowledgements The authors express our thanks to Sir Iain Chalmers for his presence and input at the workshop. The lead author wishes to express his gratitude to all participants in the workshop and to the conference organisers (International Society for Evidence-Based Health Care and Gruppo Italiano per la Medicina Basata sulle Evidenze) for the opportunity to lead it. Fiona Cowdell is funded by a National Institute for Health Research (NIHR) Knowledge Mobilisation Research Fellowship.

Contributors DN conceived the idea for the manuscript and led the development and write up. All authors contributed to the selection of included papers and manuscript write up. All authors agreed upon the final submitted version of the manuscript.

Funding The authors have not declared a specific grant for this research from any funding agency in the public, commercial or not-for-profit sectors.

Competing interests DN has received expenses and fees for his media work. He holds grant funding from the NIHR School of Primary Care Research and the Royal College of General Practitioners. On occasion, he receives expenses for teaching EBM. ISW reports personal fees from various universities and hospitals around Indonesia for teaching EBM, outside the submitted work. SC occasionally receives expenses for teaching EBM at academic conferences and hospitals around Japan. EJ receives a regular income for his employed NHS work through Yealm Medical Centre and PenARC. He receives expenses for teaching EBM. In March 2019 he received a one-off consultancy fee for 2-days work for Zavamed (work unrelated to this article). $\mathrm{PH}$ works as a teacher in EBP and is currently conducting a $\mathrm{PhD}$ research that is funded by Avans University of Applied Science. He receives expenses for lectures at seminars and workshops on EBP. HA has received funding from Health Education England to attend the EBHC 2019 meeting. She is also a visiting tutor of Evidence-Based Child Health at the UCL Great Ormond Street Institute of Child Health, London. RCB works as a teacher in EBP and receives a regular income for her employed NIPH (Department of Reviews and health technology assessments) work. None to declare - AL, WMB, C-CC, FB, CE, HTM, SGJ, RT, M-LELB, LP, AKS, PGvP, FB, KAOT, LA.

Patient consent for publication Not required.

Provenance and peer review Not commissioned; externally peer reviewed.
ORCID iDs

David Nunan http://orcid.org/0000-0003-4597-1276

Ching-Chi Chi http://orcid.org/0000-0001-5699-0283

Susanne Grødem Johnson http://orcid.org/0000-0002-2500-8952

Rachel Thompson http://orcid.org/0000-0003-2976-9078

Marie-Louise EL Bartelink http://orcid.org/0000-0001-9278-1163

Kari AO Tikkinen http://orcid.org/0000-0002-1389-8214

Peter Hoegen http://orcid.org/0000-0002-8217-3049

\section{References}

1 Nunan D, O'Sullivan J, Heneghan C, et al. Ten essential papers for the practice of evidence-based medicine. Evid Based Med 2017;22:202-4.

2 Dawes M, Summerskill W, Glasziou P, et al. Sicily statement on evidencebased practice. BMC Med Educ 2005;5:1.

3 Gabbay J, le May A. Evidence based guidelines or collectively constructed "mindlines?" Ethnographic study of knowledge management in primary care. BMJ 2004;329:1013-1010.

4 Albarqouni L, Hoffmann T, Straus S, et al. Core competencies in evidencebased practice for health professionals: consensus statement based on a systematic review and Delphi survey. JAMA Netw Open 2018;1:e180281.

5 Young T, Rohwer A, Volmink J, et al. What are the effects of teaching evidence-based health care (EBHC)? overview of systematic reviews. PLoS One 2014;9:e86706.

6 Barratt A, Wyer PC, Hatala R, et al. Tips for learners of evidence-based medicine: 1. relative risk reduction, absolute risk reduction and number needed to treat. CMAJ 2004;171:353-8.

7 Wyer PC, Keitz S, Hatala R, et al. Tips for learning and teaching evidencebased medicine: introduction to the series. CMAJ 2004;171:347-8.

8 Ioannidis JPA. Why most published research findings are false. PLoS Med 2005;2:e124.

9 Straus SE, McAlister FA. Evidence-Based medicine: a commentary on common criticisms. CMAJ 2000;163:837-41.

10 Greenhalgh T, Howick J, Maskrey N, et al. Evidence based medicine: a movement in crisis? BMJ 2014;348:g3725.

11 Hoffmann TC, Montori VM, Del Mar C. The connection between evidencebased medicine and shared decision making. JAMA 2014;312:1295-6.

12 Albarqouni L, Hoffmann T, Glasziou P. Evidence-Based practice educational intervention studies: a systematic review of what is taught and how it is measured. BMC Med Educ 2018;18:177.

13 Coomarasamy A, Khan KS. What is the evidence that postgraduate teaching in evidence based medicine changes anything? A systematic review. BMJ 2004;329:1017.

14 Khan KS, Coomarasamy A. A hierarchy of effective teaching and learning to acquire competence in evidenced-based medicine. BMC Med Educ 2006;6:59.

15 Straus SE, Sackett DL. Applying evidence to the individual patient. Ann Oncol 1999;10:29-32.

16 Sackett DLHaynes B, ed. Interview in 2014 and 2015. McMaster University, 2015. https://www.jameslindlibrary.org/sackett-dl-2015/ 